Roche, Pharma, JanssenCilag, Novartis, Abbvie, Consultant of: JanssenCilag, Patrizia Sternad: None declared., Florian Popp: None declared., Peter Bartz-Bazzanella: None declared., Cay-Benedict von der Decken: None declared., Kirsten Karberg Speakers bureau: Roche, Sanofi, Abbvie, Lilly, Georg Gauler Speakers bureau: Abbvie, Gilead, Novartis, Lilly, Consultant of: Lilly, Gilead, Abbvie, Patrick Wurth Speakers bureau: Abbvie, Lilly, UCB, Medac, Susanna Spaethling-Mestekemper Speakers bureau: Abbvie, BMS, Celgene, Gilead, GSK, Hexal, Lilly, MSD, Novartis, Pfizer, Sanofi, UCB, Christoph Kuhn: None declared., Matthias Englbrecht Speakers bureau: AbbVie, Chugai, Eli Lilly, Novartis, Roche, Sanofi, Mundipharma, Paid instructor for: AbbVie, Chugai, Roche, Consultant of: AbbVie, Novartis, Roche, Sanofi, Grant/research support from: Roche, Chugai, Wolfgang Vorbrüggen: None declared., Georg Adler: None declared., Martin Welcker Speakers bureau: Abbvie, Actelion, Amgen, Biogen,BMS, Berlin Chemie, Celgene, Galapagos, Gilead, GSK, Hexal, Janssen, Medac, MSD, Mundipharma, Mylan, Novartis, Pfizer, Roche, Sanofi, SOBI, UCB, Grant/research support from: Novartis, Abbvie.

DOI: 10.1136/annrheumdis-2021-eular.1353

\section{AB0495 \\ BIOMECHANICAL STRESS IN THE CONTEXT OF COMPETITIVE SPORTS TRAINING TRIGGERS ENTHESITIS}

D. Simon ${ }^{1}$, A. Kleyer ${ }^{1}$, S. Bayat ${ }^{1}$, J. Knitza ${ }^{1}$, L. Valor ${ }^{1}$, M. Schweiger ${ }^{1}$, G. Schett ${ }^{1}$, K. Tascilar ${ }^{1}$, A. Hueber ${ }^{2} .{ }^{1}$ Friedrich-Alexander University (FAU) Erlangen-Nürnberg and Universitätsklinikum Erlangen, Department of Internal Medicine 3 - Rheumatology and Immunology, Erlangen, Germany; ${ }^{2}$ Sozialstiftung Bamberg, Section Rheumatology, Erlangen, Germany

Background: Preclinical models have indicated that biomechanical stress can trigger entheseal inflammation (1). Furthermore, enthesitis is a hallmark of psoriatic arthritis (PsA) and spondyloarthritis ( $\mathrm{SpA}$ ), suggesting that mechanoinflammation is an important step in their pathogenesis (2). However, the relation between mechanical stress and enthesitis in humans is poorly investigated. Competitive badminton is a demanding stop-and-go sport that strains entheseal sites in particular and provides an opportunity to assess the impact of physical activity on the development of an instant inflammatory response in the entheses.

Objectives: To evaluate the influence of mechanical stress on the development of immediate enthesitis.

Methods: BEAT (Badminton Enthesitis Arthrosonography Study) is an interventional study that assessed entheses in competitive badminton players before and immediately after a 60 -minute intensive training session by ultrasound. Power Doppler (PD) signal and Gray-Scale (GS) changes were evaluated the insertions sites of both Achilles tendon, patellar tendons and lateral humeral epicondyles and quantified using a validated scoring system (3). Pre- and post-training scores were compared using linear mixed-effects models. We used interaction terms to assess possible differential effects on patellar, elbow and Achilles entheses.

Results: Thirty-two badminton players (22 men, 10 women) with an average age of $31.1 \pm 13.0$ years were included (Table 1 ). On average, they had been playing badminton for $16.2 \pm 10.1$ years. 192 entheseal sites were examined twice. The respective empirical total scores for PD examination were $0.1(0.3)$ before and $0.5(0.9)$ after training (Figure 1). Mean total GS scores were 2.9 (2.5) and 3.1 (2.5) before and after training, respectively. The mean total PD score difference of 0.4 between pre- and post -training was significant with a $p$ value of 0.0014 , whereas the $p$ value for the mean total GS score difference of 0.2 was 0.63 . Overall, seven participants $(22 \%)$ showed an increased empirical total PD score. A mixed-effects model showed a significant increase of PD scores after training, with a mean increase per site of $0.06(95 \% \mathrm{Cl} 0.01$ to $0.12, p=0.017)$.

Table 1. Baseline characteristics

\section{Demographic characteristics}

$\mathrm{N}$, total

Females, $\mathrm{N}(\%)$

Age, years (mean $\pm S D)$

Height, cm (mean value \pm SD)

Body weight, $\mathrm{kg}$ (mean value $\pm \mathrm{SD}$ )

Smoking, N (\%)

Alcohol, N (\%)

Concomitant Diseases

Inflammatory bowel disease, N (\%)

Psoriasis, $\mathrm{N}(\%)$

Uveitis, N (\%)

Diabetes mellitus, $\mathrm{N}(\%)$

Hypertension, N (\%)

Sports history

Years Badminton (mean \pm SD)
10 (31.3)

$36.1 \pm 13.0$

$178.6 \pm 9.9$

$74.7 \pm 13.5$

$11(34.4)$

24 (75.0)

0

0

0

$2(6.3)$

$16.2 \pm 10.1$

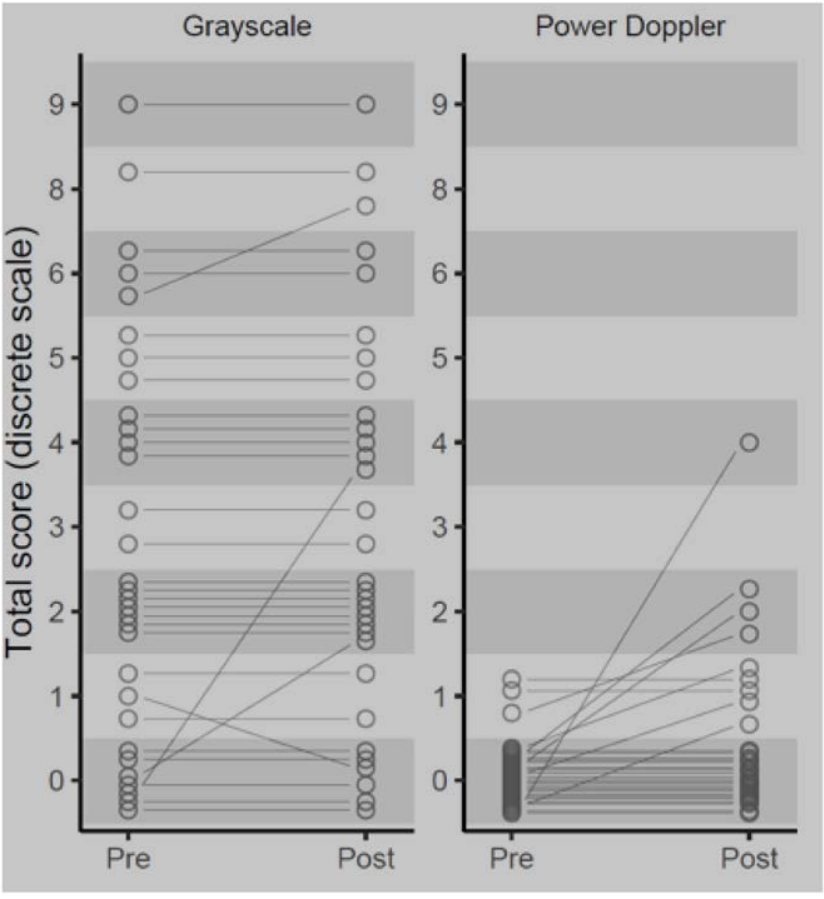

Figure 1. Ultrasound scores before and after trainingFigure 1. A Spaghetti plots depicting inividual Gray-Scale and Power Doppler ultrasound scores before and after training

Conclusion: Mechanical stress leads to rapid inflammatory responses in the entheseal structures of humans. These data support the concept of mechanoinflammation in diseases associated with enthesitis. However, while such responses may be self-contained in healthy subjects, they may be prolonged and more pronounced in certain risk groups, such as patients with PsA or SpA.

\section{REFERENCES:}

[1] Cambré I, et al. Mechanical strain determines the site-specific localization of inflammation and tissue damage in arthritis. Nature Communications. 2018; 9:4613.

[2] Schett G, et al. Enthesitis: from pathophysiology to treatment. Nat Rev Rheumatol. 2017; 13:731-741.

[3] Balint PV, et al. Reliability of a consensus-based ultrasound definition and scoring for enthesitis in spondyloarthritis and psoriatic arthritis: an OMERACT US initiative. Annals of the Rheumatic Diseases. 2018; 77:1730

Disclosure of Interests: David Simon: None declared., Arnd Kleyer: None declared., Sara Bayat: None declared., Johannes Knitza: None declared., Larissa Valor: None declared., Marina Schweiger: None declared., Georg Schett: None declared., Koray Tascilar: None declared., Axel Hueber Grant/research support from: Novartis Research Grant.

DOI: 10.1136/annrheumdis-2021-eular.1793

\section{AB0496 COMPARISON OF THE DISTRIBUTION BY DEPARTMENT OF THE PREVALENCE OF SPONDYLOARTHRITIS AND INFLAMMATORY BOWEL DISEASES IN METROPOLITAN FRANCE AND THEIR EVOLUTION BETWEEN 2008 AND 2018}

O. Fakih ${ }^{1}$, C. Prati ${ }^{1,2}$, D. Wendling ${ }^{1,3}$, F. Verhoeven ${ }^{1,2} .{ }^{1}$ Centre hospitalier régional universitaire de Besançon, Rhumatologie, Besançon, France; ${ }^{2}$ UFR Santé, Université de Franche-Comté, EA 4267 'PEPITE', Besançon, France; ${ }^{3}$ UFR Santé, Université de Franche-Comté, EA 4266 'EPILAB', Besançon, France

Background: Epidemiology of spondyloarthritis $(\mathrm{SpA})$ has been rarely described in France. One study based on a phone survey found a prevalence of $0.30 \%$ in 2001 [1], and another study based on a national cohort showed an estimated prevalence of $0.43 \%$ in 2010 [2]. To our knowledge, there is no data regarding the geographical distribution of SpA in France. Furthermore it is known that SpA occurs in up to $13 \%$ of patients with inflammatory bowel disease (IBD), and that there is a significant north-south gradient in IBD cases in France.

Objectives: To determine the prevalence of SpA and IBD in metropolitan France and compare the geographical distribution of SpA and IBD in 2008 and 2018. 
Methods: Age-and sex-standardized prevalences were collected from data freely available on the French national health insurance website concerning patients with long-term disability (LTD) \#27 (SpA) and \#24 (IBD). Data for December 31, 2008 and December 31, 2018 were collected. National data are available by diagnosis coded according to the ICD-10 classification, and data by department only concern all patients benefiting from a given LTD.

Results: National prevalence of SpA is estimated at $0.11 \%$ in 2008 (43.8\% of women, average age 50 years) and $0.27 \%$ in 2018 (54\% of women, average age 53 years). National prevalence of IBD is estimated at $0.19 \%$ in 2008 (55.6\% of women, average age 46 years) and $0.27 \%$ in 2018 (55\% of women, average age 49 years). Standardized prevalences by pathology are detailed in Table 1. Standardized prevalences by department are shown in Figure 1.

Table 1. Standardized SpA and IBD prevalence (per 100000) by disease in 2008 and 2018.

\begin{tabular}{lllll}
\hline & Ankylosing Spondylitis & Psoriatic Arthritis & Crohn's Disease & Ulcerative colitis \\
\hline 2008 & 95 & 31 & 103 & 84 \\
2018 & 181 & 57 & 153 & 126
\end{tabular}

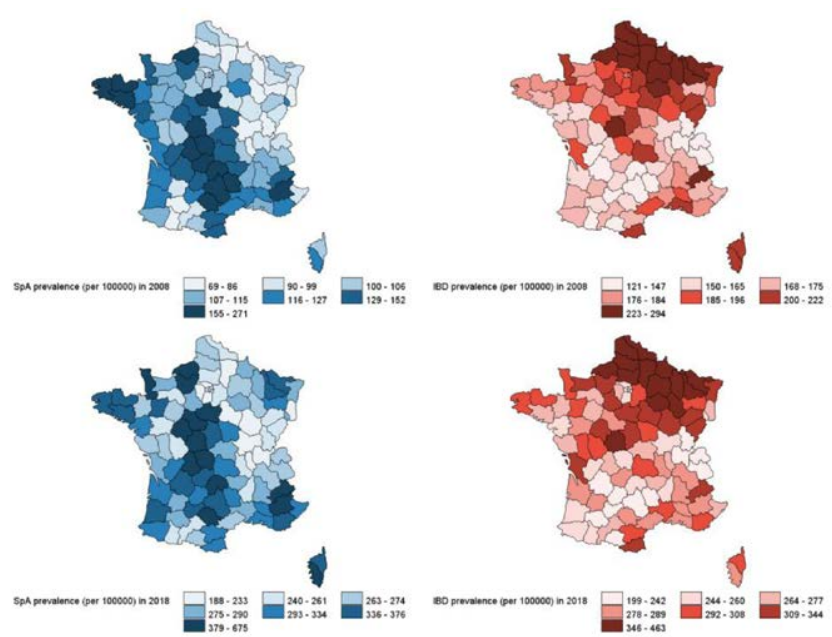

Figure 1. Standardized SpA and IBD prevalence by department in 2008 and 2018.

SpA prevalences found in this study are lower than those indicated in the literature: $0.27 \%$ versus $0.43 \%$ [2]. This may be explained by the fact that not all patients suffering from SpA or IBD benefit from LTD. Moreover, there is a 2.42-fold increase over ten years, which may correspond to the increase in prescription of biotherapies, which requires the benefit of LTD. North-south gradient in the prevalence of IBDs has been found, which is not the case for SpA, which seems to be less prevalent in the north-eastern quarter of the country. These differences in geographical distribution appear to be stable between 2008 and 2018. While IBD and SpA share many physiopathological similarities, their different geographical distributions suggest the importance of different environmental factors in the development of each condition.

Conclusion: The north-south gradient in the distribution of IBD in metropolitan France is not found in SpA. Despite an increasing prevalence, these distributions appear to be stable over time suggesting an important impact of environmental factor in the expression of these close diseases.

REFERENCES:

[1] Saraux A, Guillemin F, Guggenbuhl P, et al. Prevalence of spondyloarthropathies in France: 2001. Ann Rheum Dis 2005;64:1431-5. doi:10.1136/ ard.2004.029207

[2] Costantino F, Talpin A, Said-Nahal R, et al. Prevalence of spondyloarthritis in reference to HLA-B27 in the French population: results of the GAZEL cohort. Ann Rheum Dis 2015;74:689-93. doi:10.1136/ annrheumdis-2013-204436

Disclosure of Interests: None declared.

DOI: 10.1136/annrheumdis-2021-eular.1805

\section{AB0497 IMPACT OF COXITIS ON THE BONE MINERAL DENSITY OF THE HIP IN ANKYLOSING SPONDYLITIS}

A. Feki ${ }^{1}$, I. Sellami ${ }^{2}$, R. Akrout ${ }^{1}$, S. Ben Jemaa ${ }^{1}$, Z. Gassara ${ }^{1}$, M. Ezzeddine ${ }^{1}$, M. H. Kallel ${ }^{1}$, H. Fourati ${ }^{1}$, S. Baklouti ${ }^{1} .{ }^{1}$ Hedi Chaker Hospital, Rheumatology, Sfax, Tunisia; ${ }^{2}$ Hedi Chaker Hospital, Occupational medicine, Sfax, Tunisia
Background: Ankylosing spondylitis (AS) is an inflammatory disease, with new bone formation and ossification of the ligamentous apparatus as the primary pathological changes. The osteoporosis is coexisting with new bone formation. It is well known a common complication of this chronic disease. Hip involvement is common in AS [1].

Objectives: The objective of this work is to assess the impact of chronic inflammation of the hip (coxitis) on the bone density at this site.

Methods: This is a cross-sectional study of patients who fulfil the modified New York criteria for AS. These patients had not medical history of osteoporosis or other condition that may affect bone metabolism. Hip involvement was appreciated by physical examination and pelvic x-ray. The functional hip gene was assessed by Lequesne Algofunctional Index (LFI). Bone mineral density at the femoral site was measured using Lunar Prodigy dual-energy X-ray absorptiometry. Osteoporosis is defined when T score is $\leq-2.5 \mathrm{DS}$ (standards deviations) Osteopenia is defined when T score is $\leq-1$ DS but more than $-2.5 \mathrm{DS}$. A p value $<0.05$ was considered significant.

Results: Forty-seven AS patients were collected, 12 women and 35 men with a mean age of $43.8 \pm 13.4$ years. Smoking was noted in $25 \%$ of cases. AS clinical form was axial in 33 cases $(70.2 \%)$ and mixed (axial and peripheral) in 14 cases $(29.8 \%)$. The mean duration of AS was $15 \pm 10.9$ years. Nineteen patients $(40.4 \%)$ were on DMARD at the time of the study. Coxitis was present in 31 patients $(66 \%)$. It was bilateral in 13 cases $(42.5 \%)$. The mean of the LFI was $7.1 \pm 6.5$ with extremes of 0 to 18 . Coxitis form was early in 18 cases (40.9\%), synostosis in 15 cases $(34.1 \%)$ and destructive in 11 cases $(25 \%)$ Twenty-nine patients $(61.7 \%)$ had normal femoral bone densitometry, 13 patients $(27.7 \%)$ had osteopenia and 4 patients $(8.5 \%)$ had osteoporosis. The mean T-score value at femoral neck site was $-0.5 \mathrm{SD} \pm 1.303$ [-3- -2]. Patients with coxitis had a significantly lower $\mathrm{T}$ score at the femoral site compared to those without coxitis $(-0.77 \pm 1.31$ DS versus $0.07 \pm 1.11$ DS respectively with $\mathrm{p}=0.036$ ).

Conclusion: Our study confirms the role of chronic inflammation in the genesis of bone loss in AS. Given the risks of developing secondary complications as a result of low bone density, early management of AS should be recommended in order to control the inflammatory process and prevent the onset of osteoporosis.

\section{REFERENCES:}

[1] Toussirot E, Wendling D. Bone mass in ankylosing spondylitis. Clin Exp Rheumatol 2000:16-20.

Disclosure of Interests: None declared.

DOI: 10.1136/annrheumdis-2021-eular.1911

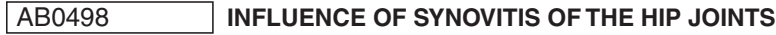 ON X-RAY PROGRESSION OF COXITIS IN AXIAL SPONDYLOARTHRITIS. RESULTS OF TWO YEARS FOLLOW-UP}

E. Agafonova ${ }^{1}$, S. Erdes ${ }^{1}$, T. Dubinina ${ }^{1}$, A. Demina ${ }^{1}$, D. Rumiantceva ${ }^{1}$, A. Smirnov ${ }^{1}$. ${ }^{1}$ V. A. Nasonova Research Institute of Rheumatology, Laboratory of spondyloarthritis and psoriatic arthritis, Moscow, Russian Federation

Background: Almost half of patients with axial spondyloarthritis (axSpA) in Russia have hip joint lesions $(\mathrm{HJ})$, but only in $7 \%$ of cases it becomes so severe and requires arthroplasty. The causes and rates of progression of coxitis have not been studied.

Objectives: To assess the relationship between disease activity and the sonographic synovitis of the hip joint with the progression of $\mathrm{X}$-ray coxitis in patients with axSpA with a 2-year follow-up.

Methods: The study included 77 patients (mean age $28 \pm 5.92$ years) with axSpA (ASAS criteria 2009), who were followed up for at least 2 years. Among them, AS (mNY criteria, 1984) had $66(86 \%)$ patients, and nonradiographic axSpA - 11 (14\%). The median duration of the disease was 30 [3-60] months, BASDAI - 4.5 [3.2; 5.9], BASFI - 2.4 [0.9; 4.8]. All patients underwent clinical examination, $\mathrm{X}$-ray and ultrasound investigation of the hip joint during the monitoring period. For ultrasound, coxitis was considered an increase in the cervical-capsular distance (CCD) of more than $7 \mathrm{~mm}$. An increase in BASRI hip by 1 stage in 2 years was considered as progression of radiographic coxitis (PRC). Results: At the time of enrollment, $66(86 \%)$ patients out of 77 patients had pain in the hip joint, and after 24 months - $48(62 \%)$ ( $p>0.05)$. At the time of inclusion, the median pain in the hip joint was $4[2 ; 5]$; severe pain $(\geq 4.0)$ had $38 \%$ of patients. The median CCD at the time of inclusion was $7.3[6.4 ; 8.2] \mathrm{mm}$, and two years later $6.6[5.9 ; 8.2] \mathrm{mm}(p>0.05)$. At the sonographic examination at the beginning of follow-up $63(82.0 \%)$ patients had coxitis, and after 2 years - 45 $(58 \%)(p<0.05)$. X-ray coxitis at the time of inclusion was present in $19(25 \%)$ patients, and after 2 years - in $48(62 \%)(p<0.05)$. Depending on the presence or absence of PRC after 2 years, the patients were divided into 2 groups (Table 1). All patients with PRC at the start of the study had sonographically diagnosed synovitis, while among those without progression, only half of them; relative risk of X-ray progression in the presence of ultrasound of synovitis $(R R)=10.5$ ( $p$ 